\title{
Neurosurgical injuries resulting from the 2011 tornados in Alabama: the experience at the University of Alabama at Birmingham Medical Center
}

\author{
Clinical article
}

\author{
Joseph H. Miller, M.D., Holly A. Zywicke, M.D., James B. Fleming, M.D., \\ Christoph J. Griessenauer, M.D., Thomas R. Whisenhunt, M.D., Ph.D., \\ Mamerhi O. Okor, M.D., Mark R. Harrigan, M.D., Patrick R. Pritchard, M.D., \\ AND Mark N. HadLey, M.D.
}

\author{
Department of Surgery, Division of Neurosurgery, University of Alabama at Birmingham Medical \\ Center, Birmingham, Alabama
}

\begin{abstract}
Object. The April 27, 2011, tornados that affected the southeastern US resulted in 248 deaths in the state of Alabama. The University of Alabama at Birmingham (UAB) Medical Center, the largest Level I trauma center in the state, triaged and treated a large number of individuals who suffered traumatic injuries during these events, including those requiring neurosurgical assessment and treatment.

Methods. A retrospective review of all adult patients triaged at UAB Medical Center during the April 27, 2011, tornados was conducted. Those patients who were diagnosed with and treated for neurosurgical injuries were included in this cohort.

Results. The Division of Neurosurgery at UAB Medical Center received 37 consultations in the 36 hours following the tornado disaster. An additional patient presented 6 days later, having suffered a lumbar spine fracture that ultimately required operative intervention. Twenty-seven patients $(73 \%)$ suffered injuries as a direct result of the tornados. Twenty-three $(85 \%)$ of these 27 patients experienced spine and spinal cord injuries. Four patients $(15 \%)$ suffered intracranial injuries and 2 patients (7\%) suffered combined intracranial and spinal injuries. The spinal fractures that were evaluated and treated were predominantly thoracic $(43.5 \%)$ and lumbar $(43.5 \%)$. The neurosurgery service performed 14 spinal fusions, 1 ventriculostomy, 2 halo placements, 1 diagnostic angiogram, 1 endovascular embolectomy, and 1 wound debridement and lavage. Twenty-two patients $(81.5 \%)$ were neurologically intact at discharge and all but 4 had 1 year of follow-up. Three patients had persistent deficits from spinal cord injuries and there was 1 death in a patient with multisystem injuries in whom no procedures were performed. Two patients experienced postoperative complications in the form of 1 wound infection and 1 stroke.

Conclusions. The April 27, 2011, tornados in Alabama produced significant neurosurgical injuries that primarily involved the spine. There were a disproportionate number of patients with thoracolumbar fractures, a finding possibly due to the county medical examiner's postmortem findings that demonstrated a high prevalence of fatal cervical spine and traumatic brain injuries. The UAB experience can be used to aid other institutions in preparing for the appropriate allotment of resources in the event of a similar natural disaster.

(http://thejns.org/doi/abs/10.3171/2013.3.JNS121656)
\end{abstract}

\section{KEY WoRdS • tornado • trauma • spine injury • spinal cord • traumatic brain injury}

$\mathrm{T}$ ORnADOS in America are relatively common occurrences and can be incredibly destructive. Tornados form within a type of cumulonimbus cloud named supercells that rotate in a counter-clockwise direc-

\footnotetext{
Abbreviations used in this paper: AIS = American Spinal Injury Association Impairment Scale; CDC = Centers for Disease Control and Prevention; ICA = internal carotid artery; $\mathrm{MCA}=$ middle cerebral artery; PLIF = posterior lumbar interbody fusion; $\mathrm{SAH}=$ subarachnoid hemorrhage; $\mathrm{SDH}=$ subdural hematoma; TLICS = Thoracolumbar Injury Classification and Severity Score; TLIF = transforaminal lumbar interbody fusion; TLSO = thoracic lumbosacral orthosis; $\mathrm{UAB}=$ University of Alabama at Birmingham.
}

tion in the Northern Hemisphere. These supercells can generate tornados that average 250 feet across and generally travel several miles. Wind speeds encountered in supercells are typically between 100 and 150 miles per hour (www.wikipedia.org). The 206 confirmed tornados across the southeastern US on April 27, 2011, were much more powerful than the average tornado. The Northern Alabama tornado, measuring EF5 on the Enhanced Fujita Scale, had wind speeds in excess of 205 miles per hour, was 1.25 miles wide, and traveled 132 miles. ${ }^{19}$ This tornado left a path of destruction over 105,000 acres. The Tuscaloosa-Birmingham tornado, affecting the primary catchment area of the UAB, was rated an EF4. ${ }^{1}$ This tor- 
nado caused a total of $\$ 2.2$ billion in damages, and resulted in 64 casualties (www.wikipedia.org). ${ }^{8}$ In total, on April 27, 2011, there were 62 tornadoes in the state of Alabama (Fig. 1), which killed 248 people, affected 44,000 , and resulted in more than $\$ 4$ billion of negative economic impact.

The UAB Medical Center, the largest Level I trauma center in the state, triaged and treated a large number of individuals who suffered traumatic injuries during the tornados on April 27, 2011. Community hospitals were also affected and recognition of their contributions to the care of these patients is warranted.

\section{Methods}

A retrospective review was conducted of all adult patients triaged at UAB Medical Center during the tornados occurring in Alabama on April 27, 2011. Patients diagnosed with and treated for neurosurgical injuries were included in this cohort. The inclusion criteria required that the patients were injured during the tornados or as a direct result of the immediate postimpact activities, such as cleanup and evacuation. This project was submitted to The UAB Institutional Review Board for Human Use and was determined to be exempt from requiring informed consent based on the use of deidentified data.

\section{Results}

The Division of Neurosurgery at the UAB Medical
Center received 37 consultations in the 36 hours following the tornado disaster. An additional patient presented 6 days later, having suffered a lumbar spine fracture ultimately requiring operative intervention. Twenty-seven patients $(73 \%)$ suffered injuries as a direct result of the tornados (Tables 1-3). The patients were predominantly Caucasian (92.6\%) and 13 were women (48\%). The age distribution was relatively uniform across age groups ( $\mathrm{p}$ $=0.0086$ ), with a mean age of $43.3 \pm 14.9$ years (range 16-72 years).

Twenty-three $(85 \%)$ of 27 patients experienced spine and spinal cord injuries. Four patients (15\%) suffered intracranial injuries and 2 patients $(7 \%)$ had combined intracranial and spinal injuries (Tables 1 and 2). Sixteen patients (59\%) required operative intervention, with 9 of these procedures performed in the first 8 hours after the tornadoes occurred. All operations with the exception of a wound revision were performed within 24 hours after the tornadoes struck the area. The neurosurgery service performed 14 spinal fusions, 1 ventriculostomy, 2 halo placements, 1 diagnostic angiogram, 1 endovascular arterial thrombectomy, and 1 wound debridement and lavage (Fig. 2).

Patients presented with a wide variety of fractures as a result of being thrown or crushed during the tornado. Spinal fractures evaluated and treated were predominantly thoracic $(n=10,43.5 \%)$ and lumbar $(n=10,43.5 \%$; Table 3). Fourteen patients required surgical fusion for burst $(n=6)$, Chance $(n=3)$, combined C1-2 $(n=1)$, Type II odontoid ( $\mathrm{n}=1)$, and bilateral lumbar facet fractures ( $\mathrm{n}$

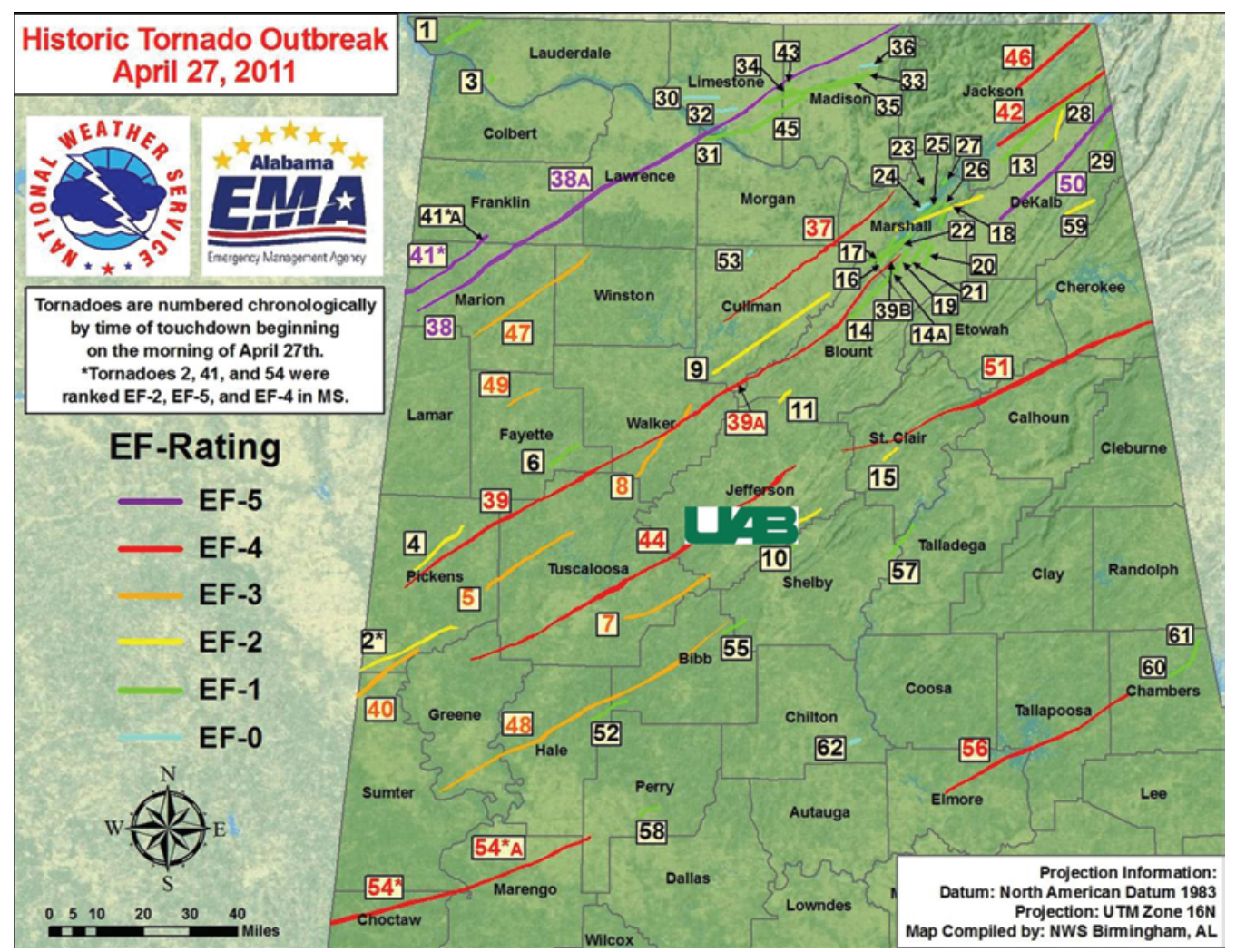

FIG. 1. National Weather Service Map illustrating the location and severity of the April 27, 2011, tornados in relation to the UAB Medical Center. Modified from: http://www.srh.noaa.gov/bmx/?n=event_04272011. 
TABLE 1: Patients with cranial injuries as a result of the April 27, 2011, tornados in Alabama*

\begin{tabular}{|c|c|c|c|c|c|c|}
\hline $\begin{array}{l}\text { Case } \\
\text { No. }\end{array}$ & $\begin{array}{l}\text { Age (yrs), } \\
\text { Sex }\end{array}$ & $\begin{array}{l}\text { Neurological } \\
\text { Injury/Findings }\end{array}$ & $\begin{array}{l}\text { Neurosurgical } \\
\text { Treatment }\end{array}$ & Other Injuries & $\begin{array}{l}\text { Neurological } \\
\text { Outcome }\end{array}$ & Complications \\
\hline 1 & $35, \mathrm{M}$ & $\begin{array}{l}\text { rt cerebral contusions w/ diffuse } \\
\text { traumatic SAH }\end{array}$ & $\begin{array}{l}\text { external ventricular } \\
\text { drain }\end{array}$ & $\begin{array}{l}\text { chest trauma, sigmoid colon in- } \\
\text { jury \& hemoperitoneum, It } \\
\text { fibular fx \& compartment syn- } \\
\text { drome, pelvic trauma }\end{array}$ & $\begin{array}{l}\text { complete neurological } \\
\text { recovery }\end{array}$ & none \\
\hline 2 & $46, F$ & open depressed skull fx & $\begin{array}{l}\text { irrigation \& debride- } \\
\text { ment }\end{array}$ & none & $\begin{array}{l}\text { complete neurological } \\
\text { recovery }\end{array}$ & none \\
\hline 4 & $55, \mathrm{M}$ & rt tentorial \& parafalcine SDH & none & rt fibula fx & $\begin{array}{l}\text { complete neurological } \\
\text { recovery }\end{array}$ & none \\
\hline
\end{tabular}

${ }^{*} \mathrm{fx}=$ fracture; $N A=$ not applicable.

$=1)$; 1 patient suffered a fracture dislocation of L1-2 resulting in spondyloptosis (Fig. 3). The nonoperative fractures $(\mathrm{n}=12,44 \%)$ consisted of 1 patient requiring halo immobilization without subsequent internal fixation and fusion for multilevel cervical spine fractures. Three patients were discharged with external orthosis in the form of cervical collars $(\mathrm{n}=2)$ and a TLSO $(\mathrm{n}=1)$. Eight patients $(33 \%)$ were believed to have clinically insignificant fractures and required no bracing.

Surgical treatment of the cervical, thoracic, and lumbar fractures $(\mathrm{n}=13)$ was varied and in 3 patients $(23 \%)$ involved a multidisciplinary approach. These 3 patients required corpectomies at T-12 $(n=1)$ and L-1 $(n=2)$. One patient with an L-1 burst fracture required a corpectomy, anterior and posterior internal fixation, and fusion. The remaining 2 patients had no adjacent-level fractures and were fused ventrally over the adjacent levels. The fusion constructs in 2 patients were augmented with a TLIF $(n=$ $1)$ and a PLIF $(n=1)$ for traumatic spondylolisthesis. The Type II odontoid fracture was treated with an odontoid screw. One patient underwent halo placement and subsequent $\mathrm{C} 1-2$ fusion for combined $\mathrm{C}-1$ and $\mathrm{C}-2$ fractures. In total, 14 patients received fusions over 49 levels as a result of this tremendous natural disaster.

The number of skull fractures and intracranial injuries observed was surprisingly low. One patient required a ventriculostomy for a severe head injury. This patient returned to work and was without residual deficit by the 4-month follow-up clinic visit. One open skull fracture was closed by the neurosurgery service at the bedside and required no operative intervention.

Patient outcomes varied; there was 1 death in a patient with diffuse axonal injury and multisystem organ injury in whom no procedures were performed. One patient experienced a postoperative wound infection following a multilevel spinal fusion. Pseudomonas aeruginosa was cultured from the wound and the patient underwent 3 washout procedures. One patient had a left MCA stroke on postoperative Day 2 following a thoracic fusion for TLICS Grade 7 T-9 and T-10 Chance fractures. ${ }^{13}$ The patient was urgently taken to the angiography suite where a mechanical thrombectomy of the MCA was performed and partial recanalization was achieved. The patient had significant blunt chest trauma, and the stroke was attributed to a likely cardioembolic mechanism. The patient's expressive aphasia and hemiparesis improved following a prolonged inpatient rehabilitation. Upon discharge he was ambulating as far as 225 feet and was appropriately answering questions. Three patients presented with significant spinal cord injuries and only 1 did not improve postoperatively. Four patients (14.8\%) were lost to follow-up, but all were neurologically intact at hospital discharge.

\section{Discussion}

The April 27, 2011, tornados resulted in 248 deaths in the state of Alabama. ${ }^{8}$ The Division of Neurosurgery at UAB Medical Center received 27 consultations for tornado-related neurosurgical injuries. Tornado-related injuries are injuries that occur during a tornado as a result of the tornado's direct impact or immediate postimpact activities. The majority of injuries were the result of being thrown or crushed while taking cover. The mechanisms of injury were oftentimes incredible. Many patients suffered significant injuries while using their bodies to protect their children or loved ones. Many were found outside of their homes and some were found more than 100 yards from where they had taken cover. The CDC found that $40 \%$ of the dead were found outside their homes. ${ }^{8}$

The injuries suffered were a testament to the power of these storms. The National Oceanic and Atmospheric Association released an assessment of the atmospheric conditions that set the stage for the largest tornado outbreak in history. They found that a low-pressure cold front moving across the Great Plains collided with a very unstable, moist atmosphere in the Southeast, setting the perfect stage for tornado development. ${ }^{17}$ The result was the most prolific month of tornados in recorded history. In the southeastern US there were 206 tornados on April 27, 2011, and 62 occurred in the state of Alabama (www. wikipedia.org). The number of tornados coupled with their severity produced the most tornado-related deaths since the great Tri-State Tornado of 1925 that produced 695 confirmed fatalities (www.wikipedia.org). 


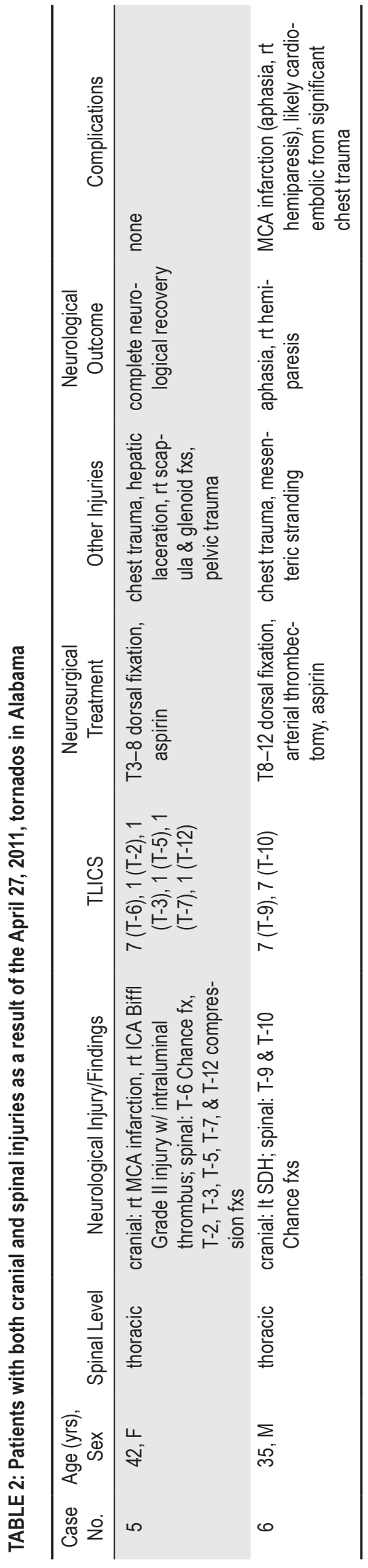

Head, spine, and orthopedic injuries are the most common tornado-related injuries requiring hospital admission. ${ }^{2,3,5-7,9-12,14-16,19,20}$ The literature regarding tornadorelated traumatic brain and cervical spinal cord injuries cites a mortality rate as high as $82 \% .^{6,14,16}$ The mortality rate for patients surviving to reach our neurosurgical service during these tornados was $3.7 \%$. The final CDC mortality report listed traumatic brain injury as the cause of death for $21.9 \%$ of fatalities, the vast majority of whom never arrived at a hospital. ${ }^{8}$ These patients had significant injuries and either died immediately or were unable to survive the length of time required to identify and transport hundreds of patients during this natural disaster.

Reported risk factors for injuries include poor building anchorage such as that found with mobile homes, a location other than in a basement, advanced age, and wind speed. Wind speed was especially correlated with morbidity and mortality, with $90 \%$ of deaths occurring with the EF4 and EF5 tornados. ${ }^{8}$ Advance warning and a lead time of more than 1 hour in many places had little impact on mortality, as these tornadoes were powerful enough to destroy even the most well-built homes and businesses. The injuries observed at UAB were largely believed to be unavoidable, because every patient had advance notice of the impending disaster.

Our findings with respect to the most frequent types of injuries differed from what has been previously reported. There were a disproportionate number of patients with spinal injuries $(85 \%)$ that predominantly involved the thoracolumbar region (76\%). Only a small number of patients sustained head and cervical spine injuries. This difference can be explained by both the Jefferson County medical examiner's postmortem examinations demonstrating a high prevalence of fatal cervical spine injuries (Birmingham is located in Jefferson County) and the CDC report documenting a high rate of fatal combined traumatic brain and spinal cord injuries. ${ }^{8,18}$

The experience at Children's Hospital in Birmingham demonstrated a much higher prevalence of traumatic brain injuries. ${ }^{9}$ The children injured in the tornados were in the exact location as many adults, yet they suffered different injuries. Chern et al. ${ }^{9}$ noted that 11 children required cranial operations compared with only 1 spinal fusion. Adult neurosurgeons in the community performed several emergency lifesaving operations in children. On the frontlines of such a disaster one must be prepared to save the lives of the injured, regardless of age.

The successful management of patients following these tornados was dependent on several factors. The first factor was strong institutional support and leadership. Advanced weather forecasting allowed the institution to make arrangements for multiple shifts of vital personnel to be available during the main wave of the patient influx. The postoperative recovery areas were converted to intensive care units and all elective cases were cancelled the following day. One hundred thirty-four patients were seen in the UAB emergency room; 44 suffered major trauma and 23 were admitted to the intensive care units.

Management of patients in a natural disaster is truly a multidisciplinary undertaking. The Department of Surgery at UAB Medical Center had a predefined leadership 
J. H. Miller et al.

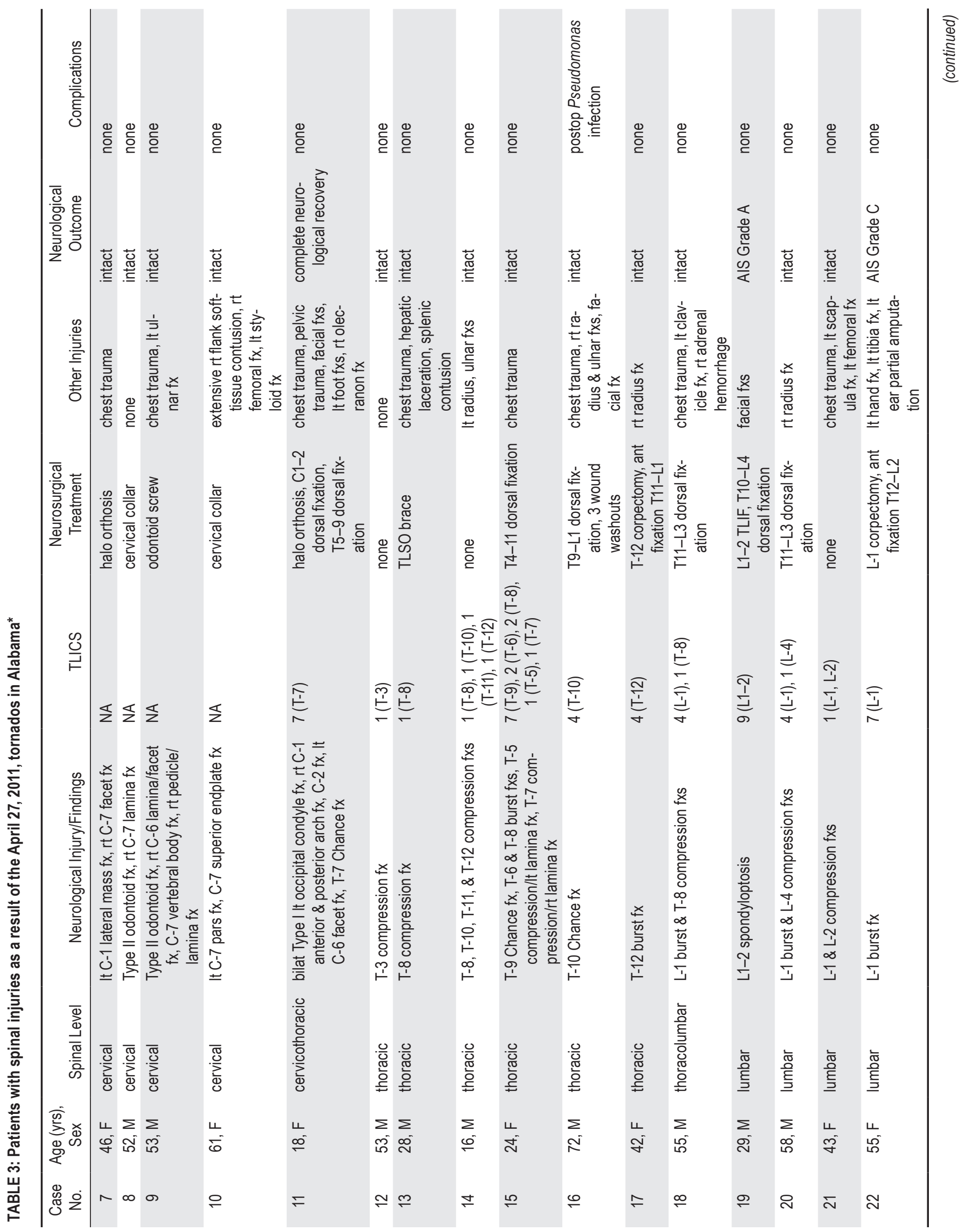




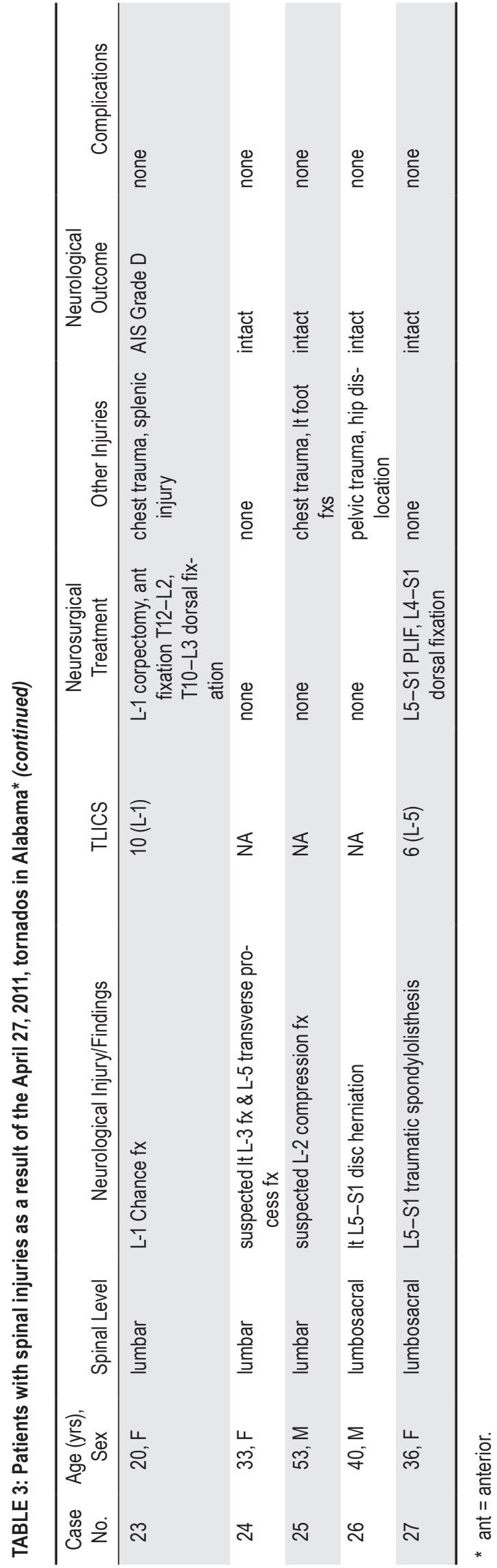

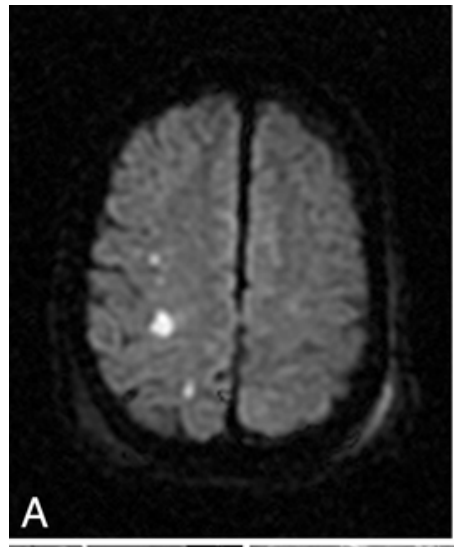
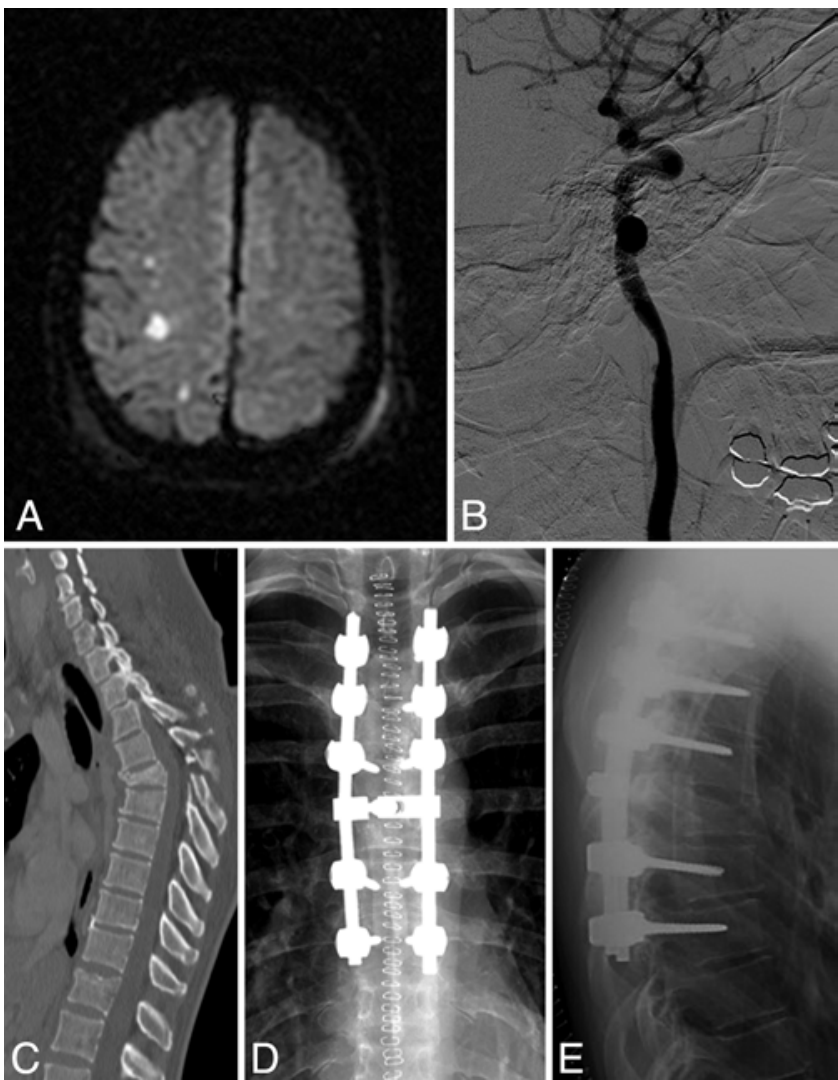

FIG. 2. Case 5. Images obtained in a 42-year-old woman who was injured in the tornado and presented with multiple thoracic fractures. This patient was found to have a left facial droop with ipsilateral facial anesthesia. Diffusion-weighted MRI (A) was consistent with showering of thrombus and the patient was urgently taken to the angiography suite, where she was found to have a right blunt traumatic Biffl Grade II ICA injury with an intraluminal thrombus ${ }^{4}$ (B). She was given $325 \mathrm{mg}$ of aspirin per day and experienced a complete neurological recovery. She additionally required a T3-8 dorsal internal fixation and fusion for a TLICS Grade 7 fracture at T-6 (C-E). Diffusion-weighted MR image (A), lateral digital subtraction angiogram $(B)$, sagittal thoracic CT scan $(C)$, anteroposterior (D) and lateral (E) plain radiographs.

hierarchy in place that allowed for the appropriate allocation of resources between the trauma, orthopedic, and neurosurgical services. Additionally, the trauma surgeons provided surgical access (via laparotomy or thoracotomy) for 3 patients requiring corpectomies. Without a team approach and fluent communication between services it would have been impossible to provide the modern neurosurgical standard of care during a natural disaster.

\section{Conclusions}

Tornados can devastate communities and place unique strains on health care providers. Neurosurgeons are a vital part of the front line of care for patients injured in tornados and need to have well-thought-out plans for dealing with these types of natural disasters, especially if practicing within an endemic area. The UAB experience can be used to aid other institutions in preparing for the appropriate allotment of resources in the event of a similar natural disaster. 

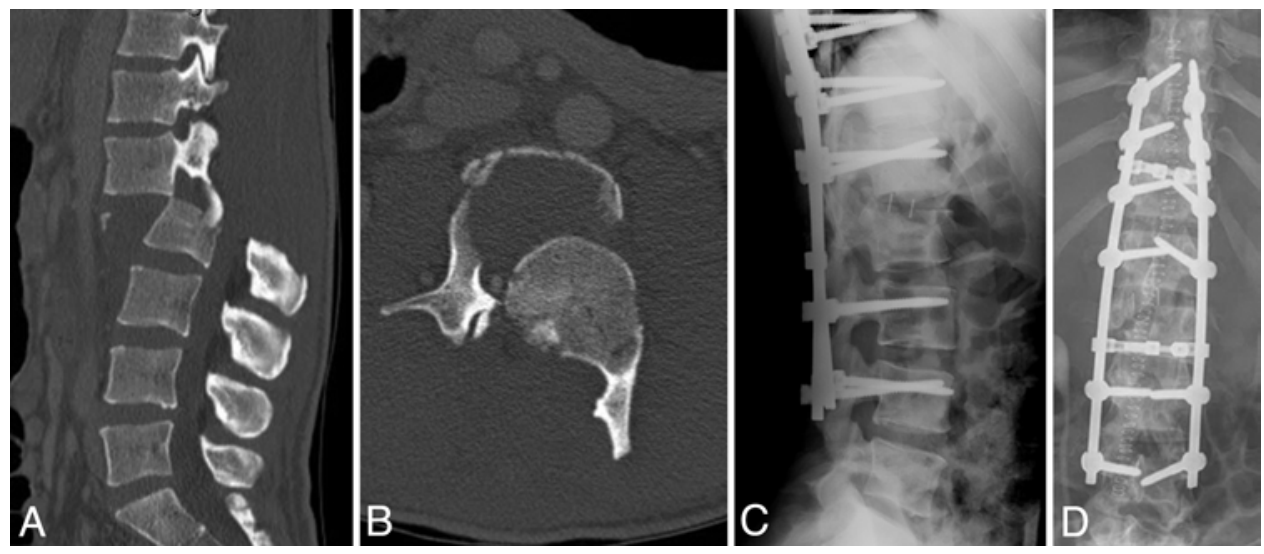

FIG. 3. Case 19. Images obtained in a 29-year-old man who sustained an impressive L1-2 fracture dislocation (A and B) resulting in spondyloptosis and an AIS Grade A on the motor examination. He required T10-L4 dorsal internal fixation (C and D). He made no neurological recovery postoperatively. Sagittal lumbar CT scan (A), axial CT scan (B), lateral (C) and anteroposterior (D) plain radiographs.

\section{Disclosure}

The authors report no conflict of interest concerning the materials or methods used in this study or the findings specified in this paper.

Author contributions to the study and manuscript preparation include the following. Acquisition of data: Zywicke, Fleming, Griessenauer, Whisenhunt, Okor, Harrigan. Analysis and interpretation of data: Hadley, Okor, Harrigan. Drafting the article: Hadley, Miller. Critically revising the article: all authors. Reviewed submitted version of manuscript: all authors. Approved the final version of the manuscript on behalf of all authors: Hadley. Administrative/ technical/material support: Fleming, Griessenauer, Whisenhunt, Pritchard. Study supervision: Hadley, Zywicke, Okor, Harrigan, Pritchard.

\section{References}

1. A Recommendation for an Enhanced Fujita Scale (EFScale): Submitted to the National Weather Service and Other Interested Users. Lubbock, TX: Texas Tech University, 2006 (http://www.depts.ttu.edu/weweb/pubs/fscale/efscale. pdf) [Accessed March 7, 2013]

2. Aguirre BE, Saenz R, Edmiston J, Yang N, Agramonte E, Stuart DL: The human ecology of tornadoes. Demography 30:623-633, 1993

3. Augustine JJ: After the storm. When a tornado tears through, just getting to its victims can be difficult. EMS World 40:28, 30-31, 2011

4. Biffl WL, Moore EE, Offner PJ, Brega KE, Franciose RJ, Burch JM: Blunt carotid arterial injuries: implications of a new grading scale. J Trauma 47:845-853, 1999

5. Bohonos JJ, Hogan DE: The medical impact of tornadoes in North America. J Emerg Med 17:67-73, 1999

6. Brenner SA, Noji EK: Head and neck injuries from 1990 Illinois tornado. Am J Public Health 82:1296-1297, 1992

7. Carter AO, Millson ME, Allen DE: Epidemiologic study of deaths and injuries due to tornadoes. Am J Epidemiol 130: 1209-1218, 1989

8. Centers for Disease Control and Prevention: Tornado-related fatalities-five states, southeastern United States, April 25-28, 2011. MMWR Morb Mortal Wkly Rep 61:529-533, 2012

9. Chern JJ, Miller JH, Tubbs RS, Whisenhunt TR, Johnston JM, Wellons JC III, et al: Massive pediatric neurosurgical injuries and lessons learned following a tornado disaster in Alabama. Clinical article. J Neurosurg Pediatr 8:588-592, 2011
10. Daley WR, Brown S, Archer P, Kruger E, Jordan F, Batts D, et al: Risk of tornado-related death and injury in Oklahoma, May 3, 1999. Am J Epidemiol 161:1144-1150, 2005

11. Donner WR: The political ecology of disaster: an analysis of factors influencing U.S. tornado fatalities and injuries, 19982000. Demography 44:669-685, 2007

12. Friedrick J: Four hospitals in the path of killer tornadoeswhat happened before ... during ... after. J Healthc Prot Manage 28:50-58, 2012

13. Lee JY, Vaccaro AR, Lim MR, Oner FC, Hulbert RJ, Hedlund $\mathrm{R}$, et al: Thoracolumbar injury classification and severity score: a new paradigm for the treatment of thoracolumbar spine trauma. J Orthop Sci 10:671-675, 2005

14. Mandelbaum I, Nahrwold D, Boyer DW: Management of tornado casualties. J Trauma 6:353-361, 1966

15. May BM, Hogan DE, Feighner KR: Impact of a tornado on a community hospital. J Am Osteopath Assoc 102:225-228, 2002

16. Millie M, Senkowski C, Stuart L, Davis F, Ochsner G, Boyd C: Tornado disaster in rural Georgia: triage response, injury patterns, lessons learned. Am Surg 66:223-228, 2000

17. NOAA National Climatic Data Center, State of the climate: tornadoes for April 2011. NOAA. (http://www.ncdc.noaa.gov/ sotc/tornadoes/2011/4) [Accessed March 7, 2013]

18. Oliver M: Alabama tornadoes: deaths reveal helmets, car seats may boost chances (slideshow). The Birmingham News. December 4, 2011. (http://blog.al.com/spotnews/2011/12/alabama_ tornadoes_--_first_in.html) [Accessed March 7, 2013]

19. Stephens $\bar{C}: 132$ miles of devastation: EF-5 tornado deadliest in United States in last 56 years. The Huntsville Times. May 8, 2011. (http://blog.al.com/breaking/2011/05/132_miles_of_ devastation_ef-5.html) [Accessed March 7, 2013]

20. Sugimoto JD, Labrique AB, Ahmad S, Rashid M, Shamim AA, Ullah B, et al: Epidemiology of tornado destruction in rural northern Bangladesh: risk factors for death and injury. Disasters 35:329-345, 2011

Manuscript submitted August 30, 2012.

Accepted March 5, 2013.

Please include this information when citing this paper: published online April 23, 2013; DOI: 10.3171/2013.3.JNS121656.

Address correspondence to: Mark N. Hadley, M.D., Department of Surgery, Division of Neurosurgery, FOT 1030, 1720 2nd Avenue South, Birmingham, Alabama 35294. email: spinal@uab.edu. 